\title{
Perancangan Sistem Informasi Penjualan Busana Muslimah Secara Online Menggunakan Metode Waterfall
}

\author{
Sri Muryani ${ }^{1}$, Tika Adilah $\mathbf{M}^{2}$ \\ ${ }^{1}$ Sekolah Tinggi Manajemen Informatika dan Komputer Nusa Mandiri \\ e-mail:sri.smy@nusamandiri.ac.id \\ ${ }^{2}$ Universitas Bina Sarana Informatika \\ e-mail: tika.tam@bsi.ac.id

\begin{tabular}{ccc}
\hline Diterima & Direvisi & Disetujui \\
$05-11-2020$ & $09-11-2020$ & $15-12-2020$ \\
\hline
\end{tabular}

\begin{abstract}
Abstrak - Busana merupakan salah satu kebutuhan pokok dalam kehidupan manusia. Dalam kegiatan seharihari tidak lepas dari yang namanya berbusana. Busana merupakan faktor penting yang menunjang penampilan. Banyak fungsi busana antara lain melindungi diri dari lingkungan, untuk menutup aurat, maupun untuk bergaya sebagai bentuk aktualisasi diri. Dalam penelitian ini dikhususkan untuk penjualan online busana muslimah beserta aksesorisnya. Penjualan online adalah kegiatan penjualan mulai dari mencari calon pembeli, melakukan promosi, penawaran barang hingga terjadi transaksi jual beli menggunakan internet sebagai alat bantu. Dengan penjualan online, penjual bisa menjangkau pelanggan yang lebih banyak, ssehingga bisa menjangkau pangsa pasar yang lebih luas. Pelanggan bisa melihat katalog busana kapan saja dimana saja tanpa terbatas oleh waktu dan wilayah. Penelitian tentang rancang bangun sistem informasi penjualan online busana muslimah menggunakan metode waterfall. Pendekatan alur hidup perangkat lunak yang disediakan oleh metode waterfall secara terurut mulai dari analisis, desain, pengkodean, pengujian, dan tahapan pendukung atau support. Dengan penelitian ini diharapkan dapat memberi kepusan tersendiri bagi pelanggan, promosi yang tanpa batas sehingga bisa meningkatkan penjualan.
\end{abstract}

Kata Kunci: Sistem Informasi Penjualan, Rancang Bangun Sistem

Abstract - Clothing is one of the basic necessities in human life. In daily activities, it cannot be separated from the name of dress. Clothing is an important factor that supports appearance. Many functions of clothing include protecting oneself from the environment, to cover one's genitals, and to style as a form of self-actualization. In this study, it is devoted to the online sale of Muslim clothing and its accessories. Online sales are sales activities ranging from finding potential buyers, conducting promotions, offering goods to buying and selling transactions using the internet as a tool. With online sales, sellers can reach more customers, so they can reach a wider market share. Customers can view the fashion catalog anytime anywhere without being limited by time and region. Research on the design of an online sales information system for Muslim clothing using the waterfall method. The software life-flow approach provided by the waterfall method is sequential, starting from analysis, design, coding, testing, and support or support stages. With this research, it is hoped that it can provide its own decisions for customers, unlimited promotion so that it can increase sales.

Keywords: Sales Information System, Design Of Information System

\section{PENDAHULUAN}

Busana merupakan salah satu kebutuhan pokok kehidupan manusia. Dalam kegiatan sehari-hari tidak lepas dari yang namanya berbusana. Busana merupakan faktor penting yang menunjang penampilan.

Banyak fungsi busana antara lain melindungi diri dari lingkungan, untuk menutup aurat, maupun untuk bergaya sebagai bentuk aktualisasi diri. Banyak profesi yang bisa dikenali dari cara berbusana. Misalnya dokter, polisi, tentara, pilot dan lainnya.

Dalam penelitian ini dikhususkan untuk penjualan online busana muslimah beserta aksesorisnya. Penjualan online adalah kegiatan penjualan mulai dari mencari calon pembeli, melakukan promosi, 
penawaran barang hingga terjadi transaksi jual beli menggunakan internet sebagai alat bantu. Dengan penjualan online, penjual bisa menjangkau pelanggan yang lebih banyak, ssehingga bisa menjangkau pangsa pasar yang lebih luas. Pelanggan bisa melihat katalog busana kapan saja dimana saja tanpa terbatas oleh waktu dan wilayah.

Penelitian tentang rancang bangun sistem informasi penjualan online busana muslimah menggunakan metode waterfall. Metode waterfall menyediakan pendekatan alur hidup perangkat lunak secara sekuensial atau terurut mulai dari analisis, desain, pengkodean, pengujian, dan tahapan pendukung atau support. Dengan penelitian ini diharapkan dapat memberi kepusan tersendiri bagi pelanggan, promosi yang tanpa batas sehingga bisa meningkatkan penjualan. Jika penjualan meningkat, otomtis bisa meningkatkan laba dan penghasilan.

Penjualan menurut (Hery, 2015, hal. 123) merupakan total jumlah yang dibebankan kepada pelanggan atas barang dagangan yang dijual perusahaan, baik meliputi penjualan tunai maupun penjualan secara kredit. Penjualan dikurangi dengan retur dan penyesuaian harga jual dan potongan penjualan akan diperoleh penjualan bersih (net sales). Website menurut (Husni, 2013, hal. 1) adalah word wide web atau yang biasa disingkat WWW merupakan kumpulan situs web yang dapat di akses di internet dimana didalamnya berisikan semua informasi yang dibutuhkan pengguna internet.

Internet menurut (Ahmadi, 2013, hal. 68) adalah jaringan komunikasi global yang menghubungkan seluruh komputer didunia meskipun berbeda sistem operasi dan mesin.

\section{METODOLOGI PENELITIAN}

Penelitian ini tentang rancang bangun sistem informasi penjulan busana muslimah menggunakan metode waterfall. Tujuan penelitian ini agar bisa menjangkau pangsa pasar yang lebih luas, sehingga bisa mendapatkan banyak pembeli untuk meningkatkan penjualan.

Metode penelitian yang digunakan adalah waterfall. Metode waterfall menyediakan pendekatan alur hidup perangkat lunak secara sekuensial atau terurut mulai dari analisis, desain, pengkodean, pengujian, dan tahapan pendukung atau support. Ilustrasi model waterfall ditunjukkan pada Gambar 1 .

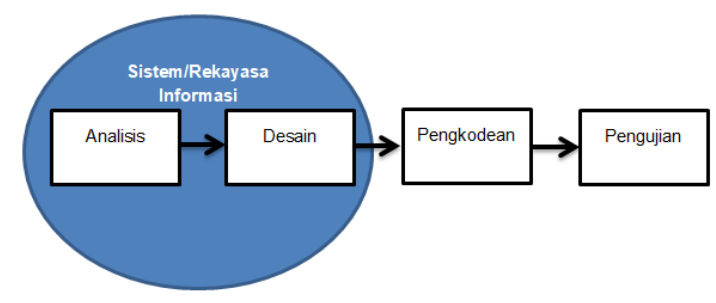

Sumber: Rosa dan Shalahuddin (2015:29)

Gambar 1. Ilustrasi Model Waterfall

\section{Analisis}

Tahap ini dilakukan secara intensif untuk menspesifikasikan kebutuhan user agar dapat dipahami oleh sistem seperti apa yang dibutuhkan oleh user.

\section{Desain}

Tahap desain adalah proses multi langkah yang fokus pada desain pembuatan program sistem termasuk struktur data, srsitektur sistem, antarmuka, dan prosedur pengkodean. Tahap ini mentranslasi kebutuhan sistem dari tahan analisis kebutuhan ke presentasi desain agar dapat di implementasikan menjadi program pada tahap selanjutnya.

\section{Pengkodean}

Pada tahap pengkodean, desain yang sudah ada di translasikan ke dalam program sistem. Hasil dri tahap pengkodean adalah program komputer sesuai denagn desain yang telag dibuat pada tahap sebelumnya.

\section{Pengujian}

Tahap pengujian memastikan bahwa semua bagian sudah diuji, baik dari segi logika atau fungsional. Pengujian dilakukan untuk meminimalisir kesalahan yang mungkin terjadi dan memastikan keluaran yang dihasilkan sesuai dengan yang dibutuhkan.

\section{HASIL DAN PEMBAHASAN}

\section{Analisa Kebutuhan}

Analisa kebutuhan software adalah proses untuk mendapatkan informasi, model dan spesifikasi perangkat lunak yang di inginkan pengguna. Pada tahap ini, harus ada interaksi aktif antara analis sistem dengan pengguna akhir.

Analisa kebutuhan perangkat lunak untuk rancang bangun sistem informasi penjualan busana muslimah, diusulkan dengan beberapa prosedur, diantaranya:

A. Kebutuhan Admin

A.1 Melakukan login dengan memasukkan username dan password.

A.2 Mengelola kategori produk berupa busana muslimah atau aksesoris.

A.3 Mengelola data produk berupa bsuana muslimah atau aksesoris.

A.4 Mengelola data member

A.5 Mengelola transaksi yang dilakukan oleh member berupa pemesanan

A.6 Mengelola data bayar dan konfirmasi

A.7 Mengelola data kirim

A.8 Mengelola testimoni 
A.9 Menampilkan dan mencetak laporan

B. Kebutuhan Pengunjung dan Member

B.1 Pengunjung dapat melihat berbagai jenis busana muslimah dan aksesorisnya.

B.2 Pengunjung bisa melihat informasi cara pemesanan dan informasi cara pembayaran.

B.3 Pengunjung dapat menihat informasi tentang kami.

B.4 Melakukan pendaftaran sebagai member jika belum terdaftar.

B.5 Melakukan login member dengan memasukkan username dan password.

B.6 Melengkapi dan melihat akun anggota, edit data, ganti password dan melihat sejarah pembelian.

B.7 Bisa melakukan transaksi pemesanan, pembayaran jika sudah menjadi member.

B.8 Mengecek keranjang belanja.

B.9 Melakukan konfirmasi pembayaran jika sudah membayar.

B.10 Dapat mengirimkan testimoni setelah melakukan transaksi.

C. Kebutuhan sistem

C. 1 Pengguna harus melakukan login dengan input username dan password untuk menjaga keamanan data

C. 2 Pengguna melakukan logout setelah selesai menggunakan aplikasi

C. 3 Sistem melakukan penghitungan total bayar untuk busana muslimah dan aksesoris yang sudah dipesan oleh member.

C. 4 Sistem melakukan update stok busana muslimah dan aksesorisnya.

\section{Desain}

\section{Use Case Diagram}

Berikut adalah use case diagram sistem informasi penjualan busana muslimah:

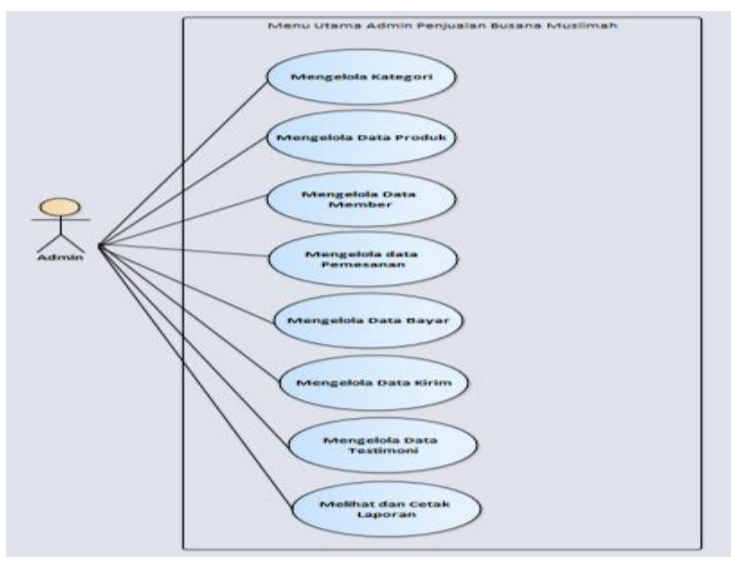

Sumber: Hasil Penelitian (2020)

Gambar 2. Use Case Diagram Menu Utama / Beranda Admin
Melalui usecase diagram terlihat menu apa saja yang bisa di akses oleh admin setelah melakukan login. Setelah login, admin bisa melakukan pengelolaan data kategori, data produk busana muslimah atau aksesoris, mengelola data member, data pemesanan, mengelola data bayar, mengelola data kirim, mengelola data testimoni, melihat dan mencetak laporan.

Tabel 1. Use Case Diagram Menu Utama / Beranda Admin

\begin{tabular}{|l|l|}
\hline \multicolumn{2}{|l|}{ Use Case narative Menu Utama Admin } \\
\hline Tujuan & $\begin{array}{l}\text { Admin dapat } \\
\text { mengakses menu utama } \\
\text { atau home }\end{array}$ \\
\hline Aktor & Admin \\
\hline Kondisi Awal & Admin telah login \\
\hline Aksi Aktor memilih & Reaksi Sistem \\
\hline $\begin{array}{l}\text { 1. Admin } \\
\text { kategori } \text { Sistem akan } \\
\text { 2. Admin memilih } \\
\text { data produk }\end{array}$ & \multicolumn{2}{|c|}{ kolom kategori, dan jenis. } \\
\hline
\end{tabular}

3. Admin memilih data member

4. Admin memilih data pemesanan

5. Admin memilih data bayar

6. Admin memilih data kirim

7. Admin memilih testimoni

2. Sistem akan menampilkan kode produk, nama, harga, kategori, stok, warna, dan keterangan

3. Sistem akan menampilkan data member berupa kode member, nama member, tgl lahir, alamat, telp, email, dan jenis kelamin

4. Sistem akan menampilkan data pemesanan berupa nomer pesan, tgl pesan, kode produk, kode member, qty, sub total, ongkir, total harga, dan bank

5. Sistem akan menampilkan data bayar berupa kode bayar, no pesan, kode member, tgl bayar, dan keterangan bayar.

6. Sistem akan menampilkan data kirim berupa no kirim, kode member, kode 

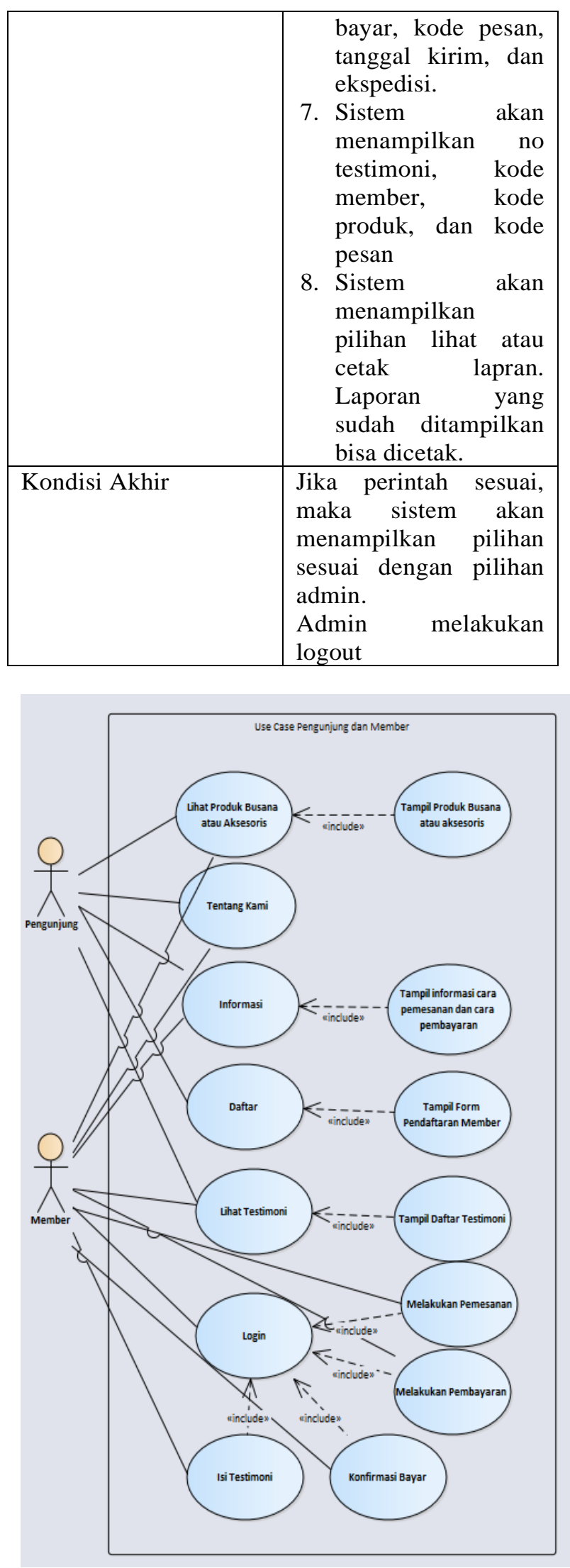

Sumber: Hasil Penelitian 2020

Gambar 2. Use Case Diagram Pengunjung dan Member
Berdasarkan usecase diagram pengunjung dan member, berikut adalag deskripsi usenya:

Tabel 1. Use Case Diagram Pengunjung dan Member

Use Case narative diagram pengunjung dan member

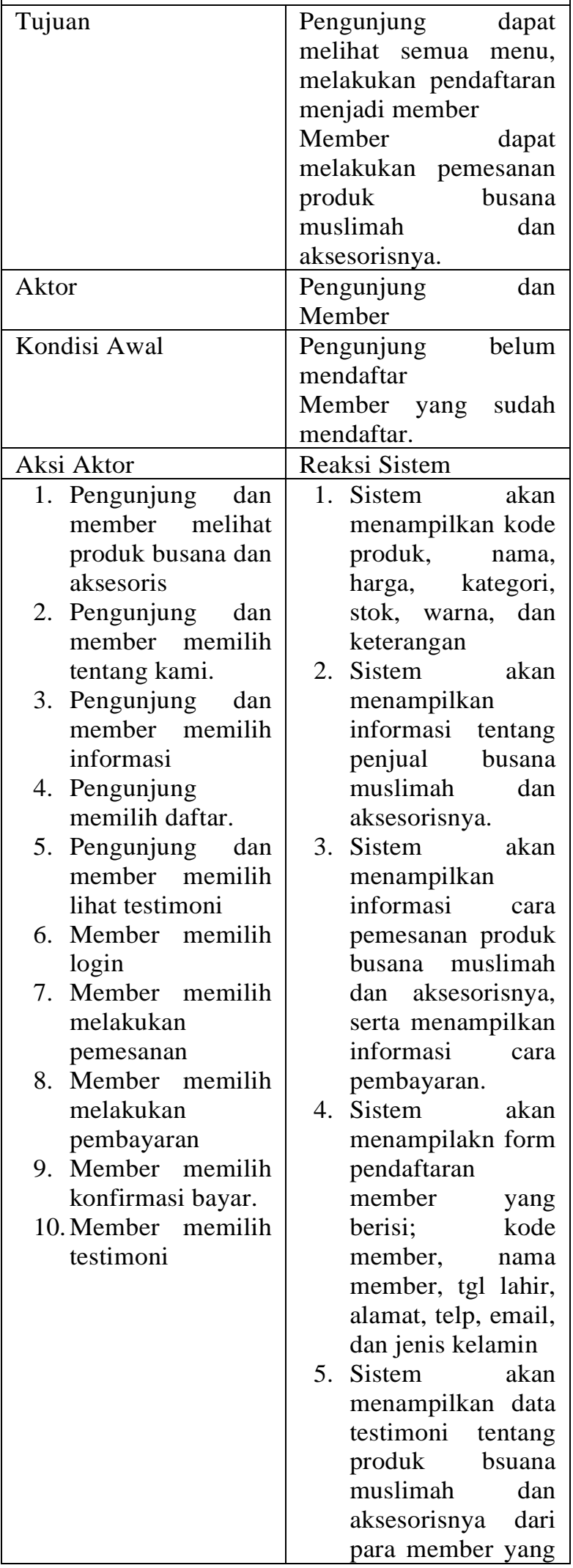




\begin{tabular}{|c|c|}
\hline & $\begin{array}{l}\text { sudah melakukan } \\
\text { transaksi } \\
\text { sebelumnya. } \\
\text { 6. Sistem akan } \\
\text { menampikan data } \\
\text { untuk } \\
\text { memasukkan } \\
\text { username dan } \\
\text { password. } \\
\text { 7. Sistem akan } \\
\text { menampilkan } \\
\text { keranjang belanja. } \\
\text { 8. Sistem akan } \\
\text { menampilkan data } \\
\text { bayar. akan } \\
\text { 9. Sistem a a a a } \\
\text { menampilkan } \\
\text { konfirmasi bayar. } \\
\text { 10. Sistem a akan } \\
\text { menampilkan } \\
\text { gambar produk, } \\
\text { member dapat } \\
\text { mengisi testimoni } \\
\text { terhadap produk } \\
\text { tersebut. }\end{array}$ \\
\hline Kondisi Akhir & $\begin{array}{lr}\text { Jika perintah } & \text { sesuai, } \\
\text { maka sistem } & \text { akan } \\
\text { menampilkan pilihan } & \text { sesuai dengan pilihan } \\
\text { pengunung } & \text { atau } \\
\text { member. } & \\
\text { member } & \text { melakukan } \\
\text { logout } & \\
\end{array}$ \\
\hline
\end{tabular}

Pada use case pengunjung dan member bisa dilihat menu yang bisa diakses oleh pengunjung, dan menu yang bisa di akses oleh member. Pengunjung dan member secara umum bisa mengakses menu lihat produk busana atau aksesoris, melihat informasi tentang kami, melihat informasi yang menampilkan informasi cara pemesanan dan cara pembayaran, menampilkan form pendaftaran member dan lihat testimoni. Pengunjung bisa menjadi member dengan syarat mengisi form pendaftaran member.

Setelah menjadi member, maka selanjutnya bisa melakukan pemesanan busana muslimah dan aksesoris dengan memasukkan pilihan produk ke keranjang belanja. Langkah selanjutnya melakukan pembayaran lalu melakukan konfirmasi bayar. Jika barang sudah diterima, member bisa memberikan testimoni terhadap produk dan layanan yang diterima.

\section{Activity Diagram}

Berikut ini adalah penggambaran activity diagram pada rancang bangun sistem informasi penjualan busana muslimah:

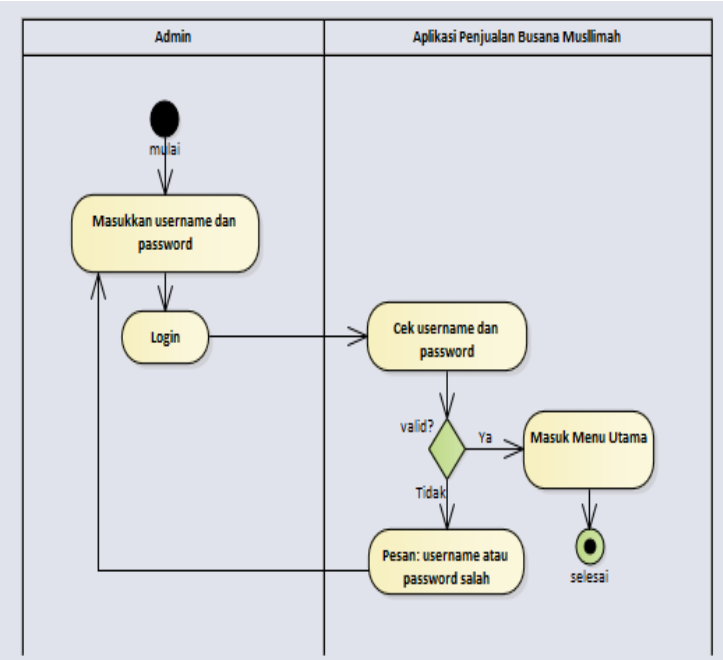

Sumber: Hasil Penelitian (2020)

Gambar 4. Activity Diagram Login

Dalam diagram login, admin atau owner memasukkan id dan password. Selanjutnya sistem akan melakukan verifikasi data saat tombol masuk ditekan. Jika data yang diinput ternyata tidak valid, sistem akan mengembalikan tampilan ke menu input id dan password. Jika data valid, maka akan masuk ke menu utama.

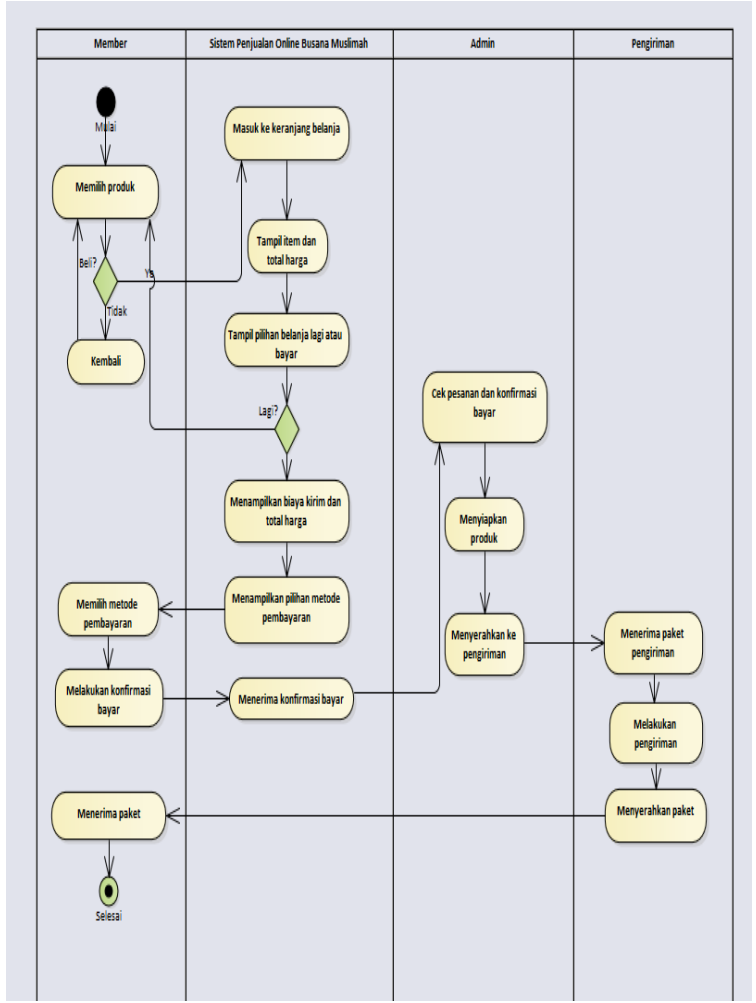

Sumber: Hasil Penelitian (2020)

Gambar 5. Activity Diagram penjualan busana muslimah dan aksesoris 
Untuk melakukan pemesanan produk busana muslimah atau aksesoris, member memilih produk, lalu memasukkan kedalam keranjang belanja. Setelah selesai, sistem akan menampilkan jumlah pembayaran. Member meilih metode pembayaran menggunakan bank apa, lalu melakukan pembayaran. Kemudian member mengisi konfirmasi bayar. Bagian admin menerima konfirmasi bayar, lalu menyiapkan produk yang sudah dipesan member. Bagian pengiriman lalu mengirimkan barang. Setelah produk diterima, member bisa mengisi testimoni.

\section{Struktur Navigasi}

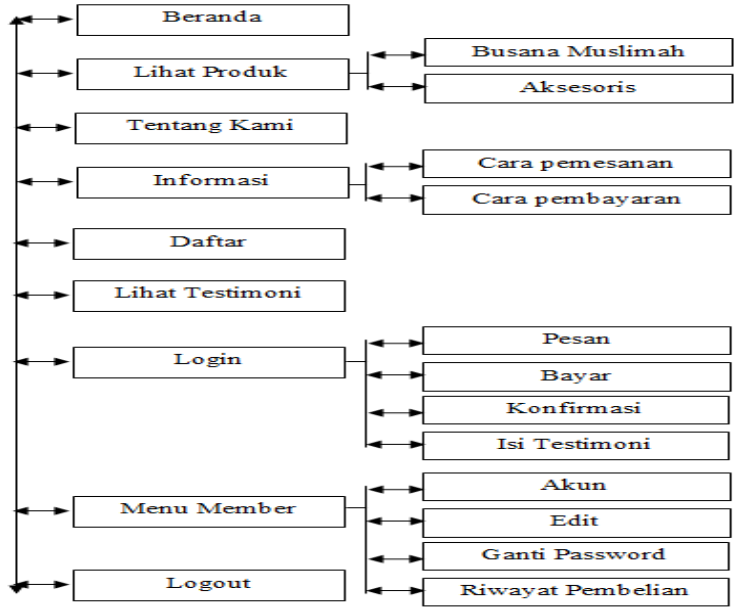

Sumber: Hasil Penelitian (2020)

Gambar 6. Struktur Navigasi Pengunjung dan Member

\section{Logical Record Struckture (LRS)}

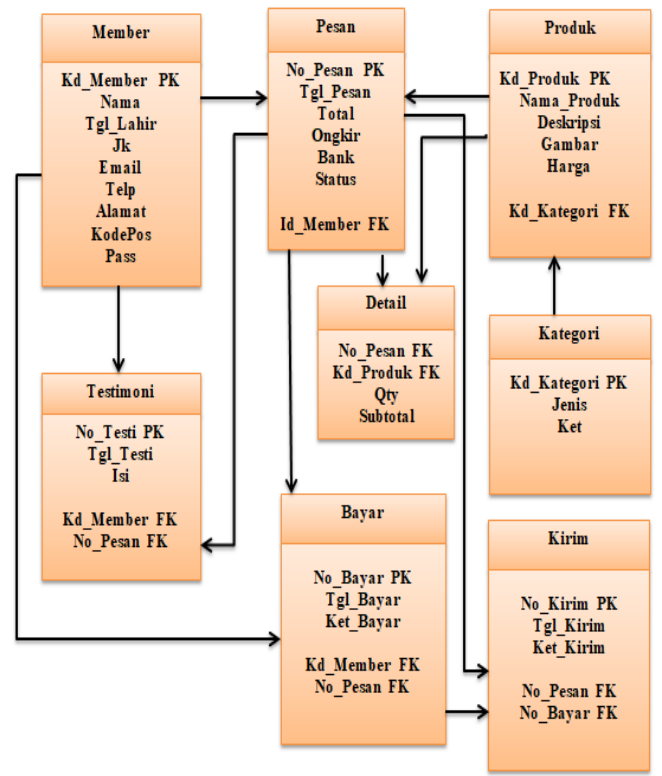

Sumber: Hasil Penelitian (2020)

Gambar 7. Logical Record Structure
Berdasarkan gambar LRS dapat kita lihat struktur database terdiri dari tabel kategori, produk, member, pesan, bayar, kirim dan testimoni.

\section{User Interface}

\section{LOGIN \\ Username}

\section{Password}

\section{Login}

Pendaftaran Baru

Sumber: Hasil Penelitian (2020)

Gambar 14. Tampilan Halaman Login

Admin dan owner mengisi username dan password pada menu login. Jika username dan password benar maka akan masuk ke menu utama. Jika username dan password yang diinputkan salah, maka tampilan akan kembali lagi ke input username dan password.

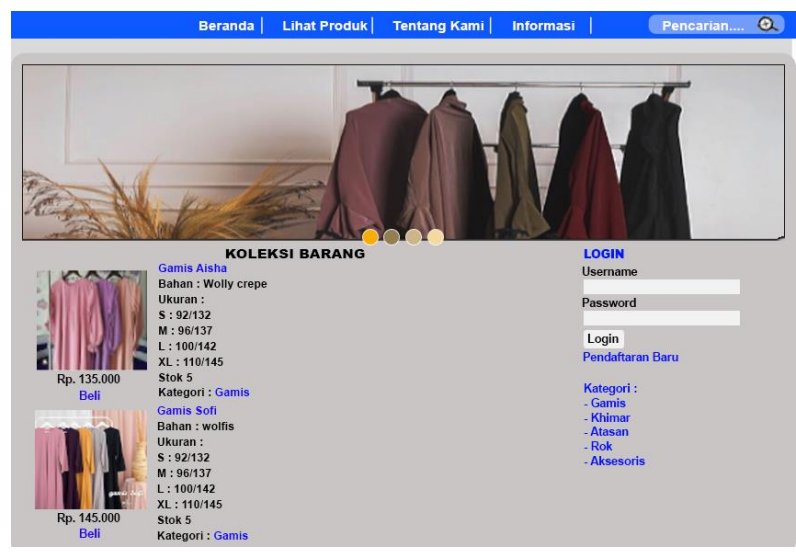

Sumber: Hasil Penelitian (2020)

Gambar 15. Tampilan Halaman Beranda

Dalam beranda bisa dilihat tampilan pilihan menu apa saja yang bisa diakses, baik oleh admin ataupun owner.

\section{KESIMPULAN}

1. Sistem penjualan busana secara online menggunakan internet sangat membantu proses promosi.

2. Penjualan busana secara online mempermudah pelanggan yang ingin membeli tanpa perlu repot keluar rumah.

3. Dengan internet, pangsa pasar lebih luas jangkauannya tanpa terbatas area daerah tertentu. 


\section{REFERENSI}

Abdulloh, R. (2015). Web Programming Is Easy. Jakarta: Elex Media Komputindo.

Ahmadi. (2013). Kolaborasi SQL dan ERD Dalam Implementasi Database. Yogyakarta: Andi.

B, B. H. (2015). Mahir Membuat Website Dengan Adobe Dreamweaver CS6, CSS, Dan JQuery. Jakarta: Andi.

Darmawan, D. D. (2013). Sistem Informasi Manajemen. Jakarta: PT. Pustaka Binawan.

Davis, G. (2013). Kerangka Dasar Sistem Informasi Manajemen. Palembang: Maxikom.

Eka, N. P. (2016). Pengantar Teknologi Informasi. Jakarta: Baduose Media.

Hasugian, H., \& Shiddiq, A. N. (2012). Perancangan Bangunan Industri Kreatif Bidang Penyewaaan Sarana Olahraga. Seminar Nasional Teknologi Informasi dan Komunikasi Terapan (SEMANTIK 2012).

Hery. (2015). Pengantar Akuntansi. Jakarta: PT. Grasindo.

Samryn, L. (2011). Pengantar Akuntansi. PT. Raja Grafindo Persada.

Sikumbang, R. (2011). Sistem Informasi Akuntansi. Ghalia Indonesia.

Sukamto, R. A., \& Shalahudin, M. (2014). Rekayasa Perangkat Lunak Terstruktur dan Beroientasi Objek. Bandung: Informatika.

Sutabri, T. (2012). Analisa Sistem Informasi. Yogyakarta.

Syahputra, R., \& Syaiful, A. (2016). Visual Programming. Yogyakarta: Mediakom 